\title{
Peculiarities of solving the problems of modern logistics in high-rise construction and industrial production
}

\author{
Anatoliy E. Rubtsov ${ }^{1}$, Elena $V$. Ushakova ${ }^{1 *}$, and Tamara V. Chirkova ${ }^{1}$ \\ ${ }^{1}$ Saint Petersburg University of Management Technologies and Economics, Institute of Management \\ Economics and Information Technology, 190103, Russia
}

\begin{abstract}
Basing on the analysis of the enterprise (construction organization) structure and infrastructure of the entire logistics system in which this enterprise (construction organization) operates, this article proposes an approach to solve the problems of structural optimization and a set of calculation tasks, based on customer orders as well as on the required levels of insurance stocks, transit stocks and other types of stocks in the distribution network, modes of operation of the in-company transport and storage complex and a number of other factors.
\end{abstract}

\section{Introduction}

The need to accelerate and expand the implementation of the logistics approach in the practice of economic activities of industrial and construction organizations, and many other industries and business activities is due to a number of objective reasons and, above all, the transition from the seller's market to the consumer (buyer) market, which requires high flexibility of the production systems in responding to the rapidly changing priorities and requirements of consumers.

The key factor in the transition of the world economy from the producer's market to the buyer's market is the formation and implementation of the logistic principles of marketing into economic activities.

This period (early 1990's) was characterized by the rapid development of military logistics, primarily in the United States. By the early 1950s, the United States basically formulated the Theory of Military Logistics. Practical significance of the developed logistics approaches in military construction, production, supply, transportation, etc. was proved by the US Army at the opening of the second front in World War II, when the principles of unified management in the supply, storage, transportation, and construction were successfully applied.

One of the oldest organizations not only in the US but also in the world is the National Association of Purchasing Management Problems, founded in 1915 and transformed in 1967 into the National Association of Procurement Agents. During the 1950s and 1970s, in Western countries, and especially in the United States, it has undergone rapid development

*Corresponding author: ushakovaev@yandex.ru 
in business logistics, many of its problems have been resolved both theoretically and in practical applications.

Famous American writer and management consultant Peter Drucker described the activity in the distribution as the most sadly neglected and in the same time most promising sphere of American business.

Along with it, those years and nowadays as well, existed a number of objective economic and technological factors explaining the need for accelerated development of logistics. Among those factors are increase in the share of services and the emergence of a large number of diverse competitive goods. This, in turn, required the search for new ways to improve commodity distribution structures, reducing costs in the processes of physical distribution.

One of the most important factors contributing to the further development of logistics thinking and increasing the efficiency of the functioning of logistics systems and supply chains was the emergence and implementation of modern computer technology along with its practical usage to solve a variety of logistics problems and tasks. On this basis, a huge number of mathematical and other methods, micro-logistics, information systems and technologies for management, planning, production were developed and introduced into logistics, which significantly shortened the time for their implementation, increased the accuracy of the solution, created all necessary conditions for a significant reduction of all types costs.

In the article the essence and possible logistic approaches and methods of solving some logistical problems and tasks are considered. It is worth to mention the insufficient of attention to those approaches so far.

Modern industrial production and high-rise construction are mechanisms of high complexity, including own technological units that produce semi-products, parts, components, assemblies, assembly units from primary goods and raw materials, and subsequently assemble finished products from these elements, both manufactured at the enterprise and purchased from other manufacturing enterprises, as well as a large number of various auxiliary units, usually combined in the term "infrastructure" of the production and, accordingly, the infrastructure of the construction. Thus, the comparison of the structural and logistic characteristics of an industrial enterprise and a construction company alongside with the operating principles and methods of improving logistical processes show the similarity of the processes taking place in the corresponding logistic systems and methods for their improvement. Taking this generalization into account, we will further consider only the peculiarities of solving the problems of production logistics on the industrial enterprise, assuming they are essentially similar to those of solving the problems of construction organization logistics.

At the present time, industrial enterprises, associations, concerns, large construction organizations quite often comprise a significant number of subsidiaries that manufacture individual units, assembly units that assemble finished products, which is clearly seen in the case of automotive companies. Lately it is common for subsidiaries being parts of associations, concerns and such to be situated at significant distances from the main factory, in different countries and even on different continents. This significantly complicates the processes of establishing logistics systems and their optimization due to a range of additional tasks requiring for optimal solution, for example, transportation of goods, creation and management of interstage inventories, optimization of transportation routes and others. Thus, the tasks of inbound logistics in relation to the separate units, assemblies, blocks etc, being parts of the finished products, are in their essence the tasks of outbound logistics in relation to the finished products. These problems and tasks often indicate the importance of an integrated approach to the analysis of the supply objectives: from suppliers of material 
resources to final consumers of finished products in accordance with their requirements and business objectives.

\section{Methods of research}

Manufacturing process of any production usually includes a large number of both elementary and complex types of activity, united by the main schedule of the enterprise. From an integrated planning perspective, the production plan is based on the sales plan and the distribution plan. At the same time, the purpose of production should be formed on the basis of corporate and marketing strategies of the enterprise, and in its content it should be outside the production cycle. Consequently, an independent (isolated) consideration of the production logistics is possible only with a business approach with given corporate goals and limitations of the external and internal environments affecting the logistics system. These goals and limitations are the basis for the operational master production scheduling of the release of a certain range of products and the appropriate logistics support for production processes.

Any production process consists of two groups of operations on material flows:

a) operations of transformation of material resources (MR) into finished products (FP), i.e. purely production operations;

b) logistical operations related to the transportation, intermediate storage and handling of MR, work-in-progress (WIP) and FP.

The analysis of these two groups of operations and functions shows that they are so closely intertwined with each other that in production logistics it is more appropriate to talk not about logistical, but about production-logistical operations, functions and systems.

Thus, the following operations, functions and systems related to the information flows can be classified as production-logistical:

- operational calendar planning with a detailed schedule of FP release;

- operational management of production and technological processes;

- quality control, maintenance of product quality standards and standards of logistics services;

- forecasting, planning and rationing of MR and WIP consumption in the production process;

- dispatching of internal technological transport;

- control and management of MR, WIP and FP stocks at all levels of the internal warehouse system and in the technological production process.

This having been said, it should be borne in mind that all operations and functions of this production-logistical complex should be carried out within the framework of the company's logistics strategy to achieve the following goals of its functioning:

- MR, WIP, FP level optimization in the production-technological cycle and warehouse system;

- optimization of the operation of the in-company transport and storage complex;

- reduction of the production-technological cycle duration;

- reduction of the logistical costs in the FP production.

Based on this complex of production-logistical operations, functions and systems and its goals set in the logistics strategy, production logistics can be defined as management of internal materials and information flows that ensures the implementation of the production program with the least total costs, while meeting all the limitations of the logistics system. This formulation is the most understandable to Russian industrial enterprises.

Given the limitations of the external environment, the logistics support of production procedures will be optimized based on the minimization of the total costs associated with the 
management of MR, WIP, FP, internal transportation, cargo handling, storage, etc. The main factors of the external environment for the manufacturing logistics are the decisions taken to supply MR, the EP distribution system, the final consumer market. The parameters of the external environment determine the numerous limitations (resource, financial, in terms of volumes and terms of delivery of MR and the conditions for their delivery, financing and lending, tax rates, customs duties, etc.) and setting actions that determine the system setting. The main parameter of setting up an internal logistics system is the dynamics of sales and demand for the company's products. In addition, it is necessary to take into account the limitations on production impacts, as well as the fact that volume and time demand indicators are usually formed basing not only on the consumers orders, but also on the required levels of stocks (transit, insurance, etc.) in the distribution network.

Production logistics processes with pre-set tuning parameters and limitations optimize the main indicators, which include:

- frequency of MR and WIP stocks turnover;

- total logistics costs;

- $\quad$ velocity of MR and WIP turnover for individual warehouses;

- costs per unit of FP;

- loading of warehouses and vehicles;

- $\quad$ risk associated with the content of internal stocks, and others.

When looking at the production logistics from the point of view of its interaction with operational management, it is necessary to pay attention to the integrating and coordinating capacity of logistics aimed at supporting the system stability of the enterprise and the entire supply chain by providing quality support for the dynamics of demand for the required volumes of products and services. This is confirmed by numerous concepts and technologies in which, in varying degrees, it is almost always possible to find elements of coordination and integration between production and supply, production and sales or the total integration of all key production-logistical processes [13].

General theory of management argues that the introduction of integrating elements into the control loop contributes to improving the stability of the system as a whole and improving the quality of management. Within that framework the production logistics can be represented as some adaptive management system that tracks the dynamics of demand and optimizes the quality parameters of production processes. Analysis and synthesis of internal logistics systems on the basis of modern management theory make it possible to obtain a lot of constructive solutions for the algorithms of logistics management, decision-making procedures, improving the quality and improving the management of material and related flows.

It is reasonable to analyze interaction of logistics and production from two points of view:

a) from the point of view of internal logistics, i.e. inventory management of MR, WIP and FP in the production process, organization of MR order procedures in structural divisions of the enterprise, management of technological transport and warehouses;

b) from the point of view of external logistics, i.e. management of key logistics functions in the MR supply and FP distribution.

Both main and auxiliary units of any industrial enterprise implement a certain set of functions (elementary and complex) that constitute the subject of production logistics. Obviously, the management of the enterprise shouldn't be artificially divided into the management of the main divisions and the management of the industrial infrastructure of the enterprise, since these components are aimed at the same goal, which is, essentially, to produce finished products in accordance with the specified production schedule and in compliance with the requirements of quality standards, and achieving maximum savings in all types of resources. 
Both for integrated logistics system in general and for production logistics, all types of links in the production structure of the enterprise involved in the management of the main and related logistical flows should be maximally coordinated and integrated.

Recently, conversions of MR into the finished products with the use of appropriate equipment, energy, information, labour resources are often called transformation processes, or processes of converting inputs to outputs (FP and/or services).

In the process of transformation, the costs of the transformation processes are added to the input costs, forming the price (prime cost) of the FP (service) production.

Implementation of the operational and logistic control and management of transformation processes requires the use of the reliable information obtained through feedback circuits. In this case the main objects of logistics management are the material and related information and financial flows that circulate between the production units of the enterprise. As there are a lot of such production units at the enterprise, from the point of view of logistics each of them can be a supplier and at the same time a consumer of certain MR, WIP and FP, forming internal logistics chains and channels. The links of these logistic chains and channels include also warehousing, transport, cargo handling and other units related to both main and auxiliary production and ensuring the existence of the material flows and the execution of the production program.

\section{Results}

The system of interaction between operational and logistics management of an enterprise proves to be optimal only when based on a production schedule that takes into account the requirements and tasks of satisfying the consumer demand and providing answers to questions about who will produce what, where, when and in what quantity. The production schedule developed on the basis of the master production schedule makes it possible to establish the volume and time characteristics of material flows differentiated for each structural production division. A classical interface with operational management for internal logistics can be represented by the duration (length) of the production period (productiontechnological cycle). One of the main tasks of internal logistics for enterprises using YIT, QR, LP logistic concepts/technologies and the like is the reduction (lead-time) of the production-technological cycle. However, it should be borne in mind that there is no need to accelerate the reduction of the production-technological cycle if there are sufficiently large reserves of FP in the distribution networks of the enterprise. This is how internal and external logistics are linked. Due to the modern market trends the time factor becomes more significant both in production and in sales, but maneuvering opportunities are significantly narrowed in the production compared to those in distribution, as most enterprises use the same advanced technologies of FP production, i.e. flexible automated and robotized equipment. Therefore, in order to reduce the production-technological cycle many enterprises seek to improve existing internal systems and technologies, introducing tools such as APS (advanced planning and scheduling technology).

The interaction of logistics and operational management can also become visible when taking into account the seasonal demand in the production of FP. This demand is not always fully predictable, therefore, in order to insure against the risk of sales loss enterprises seek to maximize the volume of FP release, which at the same time leads to an increase in costs for storage and maintenance of FP stocks both in production and in the distribution network. The task of logistics management for solving this problem is to optimize total costs in production and distribution to create seasonal stocks of FP [4]. 
What is crucial for the production logistics is the MR procurement management. A modern approach to procurement management should be universally based on YIT concept and minimizing MR stock levels at the manufacturer.

The problems of relations and interaction between logistics and production at enterprises exist in many areas and in many cases remain rather acute up to the present time. For example, for the industrial associations, concerns, etc., enterprises that assemble FP from separate products manufactured at other enterprises of the same association (holding ...), solving the "produce or buy" task is an important and frequently encountered problem of logistics and production.

The influence of the external logistics on the production in many respects also depends on a wide range of factors, which include the availability of warehouses to enterprises, the quality of warehouse equipment, the location and distance of warehouses from manufacturing enterprises and from consumers, the ways of FP transportation and storage, methods of inventory management and others.

\section{Conclusions}

From the point of view of modern operational management, the acquisition of additional competitive advantages results from the use of advanced production and logistics technologies and integrated information systems, which allow faster, better and more accurate implementation of all the production and logistics operations by means of flexible production integrated information systems. Along with the use of TQM philosophy, advanced technologies integrate production-logistical operations of an enterprise to meet consumer demand with the highest quality of products and services. The synergy of modern opportunities for universal quality management, advanced production technologies and logistics opens the way for the enterprise to achieve competitive advantages in flexibility, which includes rapid re-equipment, shortening of the production cycle, release of a new product range, acceleration of reaction to changes in consumer demand, lowering the production costs and improving the quality of products, related services and productivity.

Thus, such integration can result in an increase in the efficiency and system stability of the enterprise in the market and creation of the opportunities for introducing production innovations and for the successful implementation of the strategic tasks.

\section{References}

1. S. Agrawal, R.K. Singh, M. Qasim A literature review and perspectives in reverse logistics, Resources Conservation and Recycling, 97. 76-92 (2015)

2. Anna Sobotka, Joanna Czaja Analysis of the Factors Stimulating and Conditioning Application of Reverse Logistics in Construction Procedia Engineering, 122, 11-18 (2015)

3. Al., Adbulmohsen and R., Janaka, Proc. of the International Council for research and Innovation in Building and construction (CIB), W78-W102, (2011)

4. B.A. Anikin T.A. Rodkin Logistics and Supply Chain Management Theory and Practice. Prospekt, Moscow, 2017

5. D.J. Bowersox, D.J. Closs Logistics. Integrated supply chain. Trans. with English. (Moscow: ZAO Olimp-BUSINESS)

6. D. Bowersox, J., Closs David G. Logistics: an integrated supply chain. (Moscow, Olimp-Business Publishing House, 2017) 
7. VI Berezhnoy et al Economic mechanism for improving the efficiency of transport. Sat. scientific. works. LEEI, 35-40 (1996)

8. D. Dzh. Bauersoks, D.Dzh. Kloss, Logistika. Integrirovannaya tsep' postavok 2-e izdanie (ZAO «Olimp-BIZNES», Moskva, 2017)

9. R. Hosseini, N. Chileshe, R. Rameezdeen, S. Lehmann, Reverse Logistics for the Construction Industry: Lessons from the Manufacturing Context international Jurnal of Construction Engineering and Management, 3, 75-90 (2014)

10. V.S. Lukinskiy, E.V. Bereginoy, Logistics of motor transport: a tutorial (Finance and Statistics Moscow 2004)

11. L. M. Juan, C. Martin, R. Puertas Journal of Applied Economics 20, lssue 1, 169-192 (2017)

12. Ala-Risku, T. Mikko, International Journal of Production Economics 104, 19-29 (2006)

13. V.I. Sergeeva, Corporate logistics in questions and answers (INFRA-M, Moscow, 2013) 